Journal of Bangladesh Chemical Society, Vol. 24(2), 202-208, 2011.

DOI: 10.3329/jbcs.v24i2.9709

\title{
STUDY ON FATTY ACID COMPOSITION AND PHYSICO-CHEMICAL PROPERTIES OF NYCTANTHES ARBORTRISTIS ROOT
}

MOHAMMAD MIZANUR RAHMAN ${ }^{1 *}$ AND MOHAMMAD SHAHJAHAN ${ }^{1}$

${ }^{I}$ Department of Chemistry, Government Jagannath College (present name: Jagannath University), Dhaka-1100, Bangladesh.

\begin{abstract}
Fatty acid composition of Nyctanthes arbortristis Linn root extracted successively with light petroleum ether $\left(40-60^{\circ} \mathrm{C}\right.$ bp.)- $\mathrm{n}$-hexane and chloroform were analyzed by gas liquid chromatography (GLC). Twenty one fatty acids were identified in the Seuli root. The major saturated and unsaturated fatty acids are palmitic acid $\left(\mathrm{C}_{16: 0}, 13.97 \%\right)$ and oleic acid $\left(\mathrm{C}_{18: 1 \text {, }}\right.$ 28.43\%). Physio-chemical characteristics, such as iodine value, moisture, ash, lignin and crude fibre of the Seuli root were also determined.
\end{abstract}

Keywords: Nyctanthes arbortristis Linn, Seuli, root, fatty acid composition, gas liquid chromatography.

\section{Introduction}

Nyctanthes arbortristis Linn commonly known as Seuli a genus of family Oleaceae contains two species ${ }^{1}$. It is a large shrub which is widely cultivated throughout Bangladesh as a garden plant. It is $\mathrm{a} \mathrm{C}_{3}$ plant $^{2}$. Every part of the Seuli tree is used by the local Kobiraj (physicians) as medicinal plants to cure different diseases. The most common use of this plant is as an antihelminthic, cholagogue and laxative ${ }^{3}$. The present investigation proposes to determine the fatty acid composition of Seuli root.

\section{Experimental}

Root materials

The matured Seuli root was collected from Dhaka, Bangladesh, during the months of January, 2003. The voucher specimen (35121) of these plants was kept in the Bangladesh National Herbarium (BNH), Dhaka, Bangladesh. The collected root was cleaned, air dried and crushed mechanically.

\section{Physico-chemical studies}

Physico-chemical characteristics of root viz. iodine value (pet-ether extract), moisture, ash, lignin and crude fibre were determined by following the standard procedures ${ }^{4,5}$ and the results are shown in Table 1.

\section{Isolation of fatty acids and preparation of methyl ester}

The neutral lipids were extracted from the air-dry powdered root successively with light petroleum ether $\left(40-60^{\circ} \mathrm{C}\right)$, n-hexane and chloroform in a Soxhlet apparatus each for $22 \mathrm{~h}$, respectively. The pet-ether, hexane and chloroform extracts were mixed to equal weight $(2 \mathrm{mg})$ to analyse the fatty acid in the root. The sample was kept in a nitrogen atmosphere 
in a refrigerator. Root sample was analyzed according to the method reported by Griftin ${ }^{6}$ (1960) for esterification and fatty acid methyl ester (FAME) extraction.

\section{Preparation of Standard fatty acid methyl ester (FAME)}

Twenty seven standard free fatty acids $\left(\mathrm{C}_{6: 0}\right.$, caproic acid; $\mathrm{C}_{9: 0}$, nonanoic acid; $\mathrm{C}_{10: 0}$, capric acid; $\mathrm{C}_{11: 0}$, undecanoic acid; $\mathrm{C}_{12: 0}$, lauric acid; $\mathrm{C}_{13: 0}$, tridecanoic acid; $\mathrm{C}_{14: 0}$, myristic acid; $\mathrm{C}_{14: 1}$, myristoleic acid; $\mathrm{C}_{15: 0}$, pentadecanoic acid; $\mathrm{C}_{16: 0}$, palmitic acid; $\mathrm{C}_{16: 1}$, palmitoleic acid; $\mathrm{C}_{17: 0}$, heptadecanoic acid; $\mathrm{C}_{18: 0}$, stearic acid; $\mathrm{C}_{18: 1}$, oleic acid; $\mathrm{C}_{18: 2}$, linoleic acid; $\mathrm{C}_{18: 3}$, alpha-linolenic acid; $\mathrm{C}_{20: 0}$, arachidic acid; $\mathrm{C}_{20: 1}$, eicosenoic acid; $\mathrm{C}_{18: 4}$, octadecatetraenoic acid; $\mathrm{C}_{20: 2}$, eicosadienoic acid; $\mathrm{C}_{20: 4}$, arachidonic acid; $\mathrm{C}_{22: 0}$, behenic acid; $\mathrm{C}_{22: 1}$, erucic acid; $\mathrm{C}_{20: 5}$, timnodonic acid; $\mathrm{C}_{24: 0}$, lignoceric acid; $\mathrm{C}_{24: 1}$, nervonic acid and $\mathrm{C}_{22: 6}$, clupanodonic acid) were individually weighed. About $5 \mathrm{mg}$ of each was taken in a reaction tube and $\mathrm{BF}_{3} \mathrm{CH}_{3} \mathrm{OH}$ reagent $(5 \mathrm{~mL})$ was added ${ }^{6}$ to it. The mixture was boiled for $5 \mathrm{~min}$. Hexane $(5 \mathrm{~mL})$ was added to it and boiled for further $1 \mathrm{~min}$. After cooling the tube a solution of saturated salt was added and vortexed. Then the upper layer containing methyl esters was transferred to a vial with anhydrous sodium sulfate at the bottom. Then the ester was filtered through syringe filter and transferred to a small vial $(2 \mathrm{~mL})$. The solvent was concentrated by blowing nitrogen gas and stored in a refrigerator before analysis by GLC.

\section{Gas Liquid Chromatography (GLC)}

The fatty acid methyl esters were identified by gas liquid chromatography method using a capillary glass column $(60 \mathrm{~m} \times 0.25 \mathrm{~mm}$ ID), coated with $100 \%$ cyanopropyl polysiloxane open tubular (WCOT) fused silica (SP2340, Suplco, Bellefonte, Pennsylvania, USA) and flame ionization detector in GC-14A series (Shimadzu Co, Tokyo, Japan). Helium gas used as the carrier gas was at a flow rate of $3.5 \mathrm{~mL} / \mathrm{min}$. Air and hydrogen flow rates were 350 and $25 \mathrm{~mL} / \mathrm{min}$, respectively. The detector and injector temperatures were selected as $240^{\circ}$ and $235^{\circ} \mathrm{C}$, respectively. The oven temperature was set to $135^{\circ} \mathrm{C}$ for 14 min and heated to $230^{\circ} \mathrm{C}$ with a heating rate of $3^{\circ} \mathrm{C} / \mathrm{min}$ and maintained at this temperature for $6 \mathrm{~min}$. Data were analyzed with peak simple chromatography software

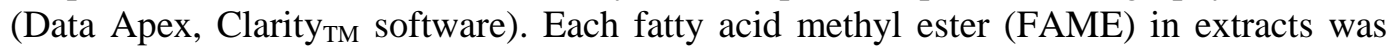
identified by comparing retention times (LIPID STANDARD, Sigma Chemical Co, St Louis, Mo, USA).

\section{Result and Discussion}

The pet-ether, hexane and chloroform extracts of Seuli root were found to be $0.33,0.18$ and 0.70 percent (dry matter basis) respectively. It is seen (Table 1) that the iodine values (Henus) of root of pet-ether extract was found to be 118.8. On the other hand, iodine values (Henus) of mixture extract (light petroleum ether - n-hexane and chloroform) of root did found to be 148.6. Both iodine values specify that pet-ether was not extracted whole fat from root. Higher iodine value indicated that Seuli root of both extracts (pet- 
ether \& mixture extract) of fats are highly unsaturated. The Seuli root was found to contain moisture, $72.5 \%$; ash, $2.6 \%$; lignin, $29 \%$ and crude fibre, $44.3 \%$.

\section{Table 1. Physico-chemical characteristics of Nyctanthes arbortristis Linn root}

\begin{tabular}{lc}
\hline Parameters & Result $\left(\mathbf{D M}^{\mathrm{a}}\right)$ \\
\hline Moisture & $72.5 \%\left(\mathrm{FM}^{\mathrm{b}}\right)$ \\
Ash & $2.6 \%$ \\
Lignin & $29 \%$ \\
Crude fibre & $44.3 \%$ \\
Iodine value (Hanus) $^{\mathrm{c}}$ & 118.8 \\
Iodine value (Hanus) $^{\mathrm{d}}$ & 148.6 \\
${\text { Pet-ether extract }\left(40-60^{0} \mathrm{C} \text { bp. }\right)}^{\text {n-Hexane extract }}$ & $0.33 \%$ \\
Chloroform extract $^{-}$ & $0.18 \%$ \\
\hline
\end{tabular}

${ }^{\mathrm{a} D M}$-Dry matter; ${ }^{\mathrm{b}} \mathrm{FM}$-Fresh matter; ${ }^{\mathrm{c}}$ Iodine value of pet-ether extract and ${ }^{\mathrm{d}}$ Iodine value of mixture extract (light petroleum ether - $\mathrm{n}$-hexane and chloroform).

The fatty acid composition of root is summarized in Table 2 . Oleic acid $\left(\mathrm{C}_{18: 1}\right)$ was the dominant unsaturated fatty acid in the root of Seuli. Major fatty acids of root are palmitic acid $\left(\mathrm{C}_{16: 0}, 13.97 \%\right)$ and oleic acid $\left(\mathrm{C}_{18: 1,}, 28.43 \%\right)$. The lowest amount $(1.03 \%-8.60 \%)$ of fifteen acids was detected in the Seuli root FAME. On the other hand, trace amount $(0.21 \%-0.44 \%)$ of four fatty acids $\left(\mathrm{C}_{9: 0}\right.$, nonanoic acid; $\mathrm{C}_{10: 0}$, capric acid; $\mathrm{C}_{11: 0}$, undecanoic acid and $\mathrm{C}_{14: 0}$, myristic acid) were detected in the Nyctanthes arbortristis root FAME. Fatty acid methyl ester of root showed the unsaturated/saturated ratio (USR) was 2.12. It's indicated that the amount of total unsaturated fatty acid was higher than the total saturated fatty acid in the root sample. However, $\mathrm{C}_{6: 0}$, caproic acid; $\mathrm{C}_{13: 0}$, tridecanoic acid; $\mathrm{C}_{14: 1}$, myristoleic acid; $\mathrm{C}_{15: 0}$, pentadecanoic acid; $\mathrm{C}_{18: 4}$, octadecatetraenoic acid and $\mathrm{C}_{20: 5}$, timnodonic acid were not identified in the sample of root.

Comparative study of fatty acid composition of Nyctanthes arbortristis Linn root, bark ${ }^{7}$ and ripe seed ${ }^{8}$

In Figure 1, our previous study of the fatty acid compositions of bark ${ }^{7}$ and ripe seed ${ }^{8}$ in Nyctanthes arbortristis Linn were taken the same (same as Seuli root sample) twenty seven standard fatty acids for identified the bark FAME of chromatographs by GLC. On the other hand, twelve standard fatty acid methyl esters of caprylic acid (C8:0), nonanoic acid (C9:0), capric acid (C10:0), undecanoic acid (C11:0), lauric acid (C12:0), myristic acid (C14:0), palmitic acid (C16:0), linoleic acid (C18:2), oleic acid (C18:1), stearic acid (C18:0), arachidic acid (C20:0) and behenic acids (C22:0) were used in the ripe seed for identified the chromatograph by GLC. 
Table 2. Fatty acid composition of the Nyctanthes arbortristis Linn root (percentage composition).

\begin{tabular}{lll}
\hline Fatty acids & Structure $^{\mathrm{a}}$ & Root $^{\mathrm{a}}$ \\
\hline Caproic acid & $\mathrm{C} 6: 0$ & $\mathrm{NF}^{\mathrm{b}}$ \\
Nonanoic acid & $\mathrm{C} 9: 0$ & 0.21 \\
Capric acid & $\mathrm{C} 10: 0$ & 0.30 \\
Undecanoic acid & $\mathrm{C} 11: 0$ & 0.31 \\
Lauric acid & $\mathrm{C} 12: 0$ & 1.03 \\
Tridecanoic acid & $\mathrm{C} 13: 0$ & $\mathrm{NF}$ \\
Myristic acid & $\mathrm{C} 14: 0$ & 0.44 \\
Myristoleic acid & $\mathrm{C} 14: 1$ & $\mathrm{NF}$ \\
Pentadecanoic acid & $\mathrm{C} 15: 0$ & $\mathrm{NF}$ \\
Palmitic acid & $\mathrm{C} 16: 0$ & 13.97 \\
Palmitoleic acid & $\mathrm{C} 16: 1$ & 1.68 \\
Heptadecanoic acid & $\mathrm{C} 17: 0$ & 1.79 \\
Stearic acid & $\mathrm{C} 18: 0$ & 2.86 \\
Oleic acid & $\mathrm{C} 18: 1$ & 28.43 \\
Linoleic acid & $\mathrm{C} 18: 2$ & 8.60 \\
Alpha-linolenic acid & $\mathrm{C} 18: 3$ & 5.97 \\
Arachidic acid & $\mathrm{C} 20: 0$ & 2.68 \\
Eicosenoic acid & $\mathrm{C} 20: 1$ & 1.45 \\
Octadecatetraenoic acid & $\mathrm{C} 18: 4$ & $\mathrm{NF}$ \\
Eicosadienoic acid & $\mathrm{C} 20: 2$ & 3.40 \\
Arachidonic acid & $\mathrm{C} 20: 4$ & 6.30 \\
Behenic acid & $\mathrm{C} 22: 0$ & 4.13 \\
Erucic acid & $\mathrm{C} 22: 1$ & 1.68 \\
Timnodonic acid & $\mathrm{C} 20: 5$ & $\mathrm{NF}$ \\
Lignoceric acid & $\mathrm{C} 24: 0$ & 4.40 \\
Nervonic acid & $\mathrm{C} 24: 1$ & 5.98 \\
Clupanodonic acid & $\mathrm{C} 22: 6$ & 4.39 \\
\hline & & \\
\hline
\end{tabular}

'Carbon number with 'zero' double bonds are saturated fatty acids, with 'one' double bonds are monounsaturated and with 'two' and 'three' double bonds are polyunsaturated fatty acid and ${ }^{\mathrm{b}} \mathrm{NF}-$ not found. 


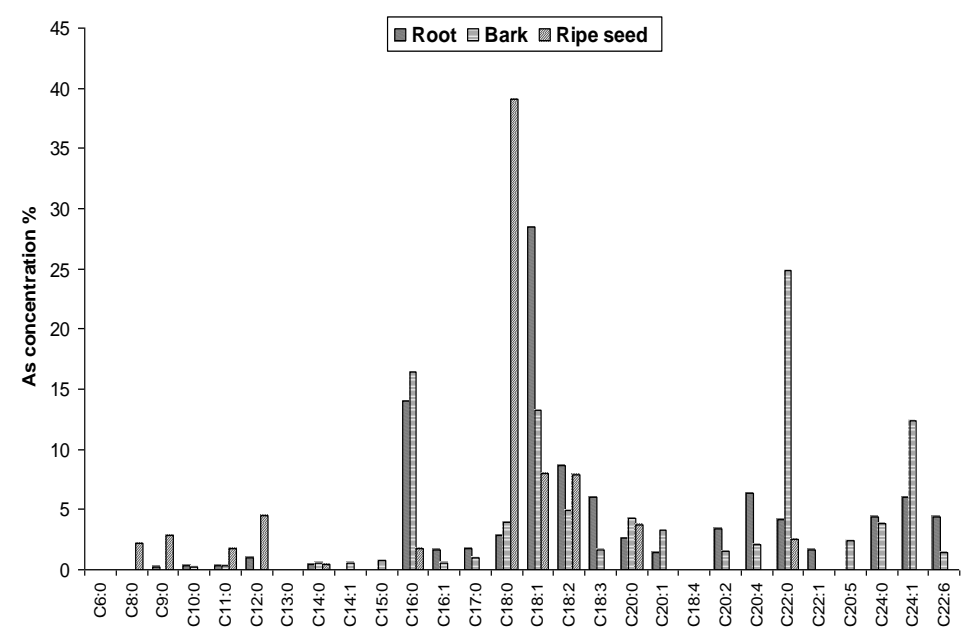

Fig. 1. Comparative study of fatty acid compositions of Seuli root, bark $^{7}$ and ripe $\operatorname{seed}^{8}$ (percentage composition)

GLC analysis of fatty acid methyl ester of root, bark and ripe seed were identified 21, 21 and 11 compounds respectively. These analysis revealed that contains Nyctanthes arbortristis root, bark and ripe seed mainly oleic acid $\left(\mathrm{C}_{18: 1,}, 28.43 \%\right)$, behenic acid $\left(\mathrm{C}_{22: 0 \text {, }}\right.$ $24.80 \%)$, stearic acid $\left(\mathrm{C}_{18: 0}, 39.06 \%\right)$ respectively. Behenic acid (C22:0) and stearic acid (C18:0), was the dominant saturated fatty acid in the bark and ripe seed FAME respectively. On the other hand, oleic acid (C18:1) was the dominant unsaturated fatty acid in the root FAME.

Highest percent (18.3\%) of omega-6 was detected in the root FAME. Only omega-6 of linoleic acid was found in ripe seed (7.89\%) FAME. Omega-3 of root was identified higher percent $(10.36 \%)$. On the other hand, lower percent $(5.35 \%)$ of omega-3 was found in bark FAME. Higher ratio of omega-6/omega-3 was detected in root (1.77) and lower ratio in bark (1.58). It indicated that higher percent of omega-6 present in root FAME then bark and ripe seed of Nyctanthes arbortristis Linn.

Comparative study of average fatty acid composition of Nyctanthes arbortristis Linn

Comparative study of TSFA, TMUFA, TPUFA of root, bark ${ }^{7}$ and ripe seed ${ }^{8}$ in Nyctanthes arbortristis Linn are shown in Figure 2. The highest total saturated fatty acid (TSFA) was 78.87 percent identified in ripe seed and lowest $(32.12 \%)$ found in root FAME. However, the total monounsaturated fatty acid (TMUFA) content of $39.22 \%$ was detected highly in the sample of root and lowest value of $10.62 \%$ identified in ripe seed 
FAME. On the other hand, the highest value of total polyunsaturated fatty acid (TPUFA) contents of 28.66 percent found was in the root. The lowest value of TPUFA (10.51\%) was detected in ripe seed FAME.

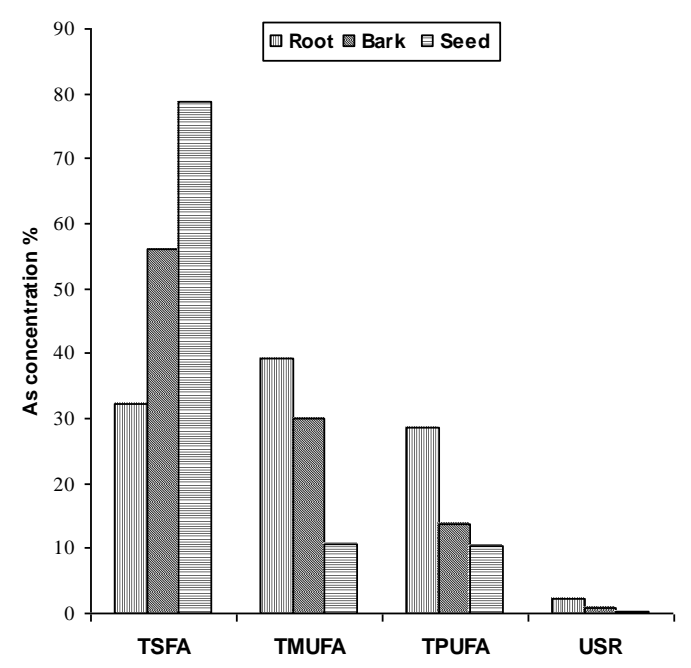

Fig. 2. Comparative study of average fatty acid composition of Nyctanthes arbortristis Linn root, bark $^{7}$ and ripe seed ${ }^{8}$ (TSFA- total saturated fatty acid; TMUFA- total monounsaturated fatty acid and TPUFA- total polyunsaturated fatty acid; USR- unsaturated/saturated ratio).

Ratio of unsaturated/saturated fatty acid (USR) was higher (2.11) in root FAME. On the other hand, lowest ratio of USR was detected in ripe seed (0.27). It is indicated that the highest unsaturated fatty acid was in root FAME and saturated fatty acid was highly present in ripe seed FAME. In this result, ripe seed FAME was the dominant saturated fatty acid and unsaturated fatty acid dominated the root FAME of Nyctanthes arbortristis Linn.

\section{Conclusion}

Nyctanthes arbortristis Linn root collected from Bangladesh were investigated as non edible fat sources for the production of industrial uses. Based on GLC analysis, twenty one types of fatty acid were identified and quantified in Nyctanthes arbortristis Linn root. Approximately $61 \%$ of fatty acids were found to be unsaturated. Palmitic acid and oleic acid were indicated as a main source of the Nyctanthes arbortristis Linn root.

\section{Acknowledgement}

Authors are thankful to the Chairman, BCSIR Laboratories, Dhaka-1205, Bangladesh for giving the permission to conduct the research work. 


\section{References}

1. E. Wallander, and V. A. Albert, Phylogeny and classification of Oleaceae based on rps 16 and tmL-F sequence data. American Journal of Botany., 2000, 87(12), 1827-1841.

2. P. G. Rao, and J. Kodandaramaiah, Association of Chlorophyll content, phyllotaxy, photosynthesis and B group vitamins in some $\mathrm{C}_{3}$ and $\mathrm{C}_{4}$ plants. Proc. Indian Acad. Sci.(Plant Sci.), 1982, 91(6), 495-500.

3. R. N. Chopra, S. L. Nayar, and I. C. Chopra, Glossary of Indian Medicinal Plants, CSIR Publication, India,1956, p. 177.

4. G. Mowlah, N. M. Sheikh and A. S. M. Kamal, A Hand Book on Edible Oils and Fats, With Special Reference To Bangladesh, ${ }^{\text {st }}$ ED.; City press, Dhaka-1000, Bangladesh,1990, p. 44.

5. Royal Charter, British Standard Methods of the Analysis of Oils and Fats. B. S. 684. British Standards Institution Incorporated, British Standards House, 2 Park ST,London, W.1., 1958.

6. R. C. Griftin, A. M. S. M. Technical Method of Analysis. $2^{\text {nd }}$ ED., Mc Graw-Hill Co. Inc., New York and London,1960, p. 299.

7. M. M. Rahman and M. Shajahan, Analysis of fatty acid composition of Nyctanthes arbortristis Linn bark by gas liquid chromatography. International Journal of Pharmaceutical Research and Development, June-2011, 3(04):1-5.

8. M. M. Rahman, S. K. Roy and M. Shajahan, Fatty acid composition of ripe seed oil of Nyctanthes arbortristis Linn. Journal of Bangladesh Academy of Sciences, June 2011, 35(1):121-124.

(Received: 2 April, 2011; Accepted : 9 August, 2011) 